\title{
ENVISIONING COASTAL FUTURES: EXPLORING ALTERNATIVE SCENARIOS FOR THE US PACIFIC NORTHWEST COASTLINE
}

\author{
Peter Ruggiero, Oregon State University,pruggier@ceoas.oregonstate.edu \\ John Bolte, Oregon State University, jbolte@oregonstate.edu \\ Janan Evans-Wilent, Oregon State University, evanswij@oregonstate.edu \\ Kai Parker, Oregon State University,parkerk@oregonstate.edu \\ Cynthia Schwartz, Oregon State University, cynthia.schwartz@oregonstate.edu \\ Katherine Serafin, Oregon State University, kserafin@coas.oregonstate.edu \\ John Stevenson, Oregon State University, jstevenson@coas.oregonstate.edu
}

\section{INTRODUCTION}

Sea level rise (SLR), changing storminess patterns, and development have exposed coastal communities to chronic coastal change and flooding hazards. Several U.S. Pacific Northwest communities are at high risk from coastal hazards and local decision makers often lack tools for developing adaptive capacity to increase resilience, particularly under climate change. Several sectors (e.g., local community groups, emergency managers, and land use planners) have recently begun to define responses to perceived increases in the frequency and magnitude of coastal hazards. Here we describe the efforts of a group of Oregon State University researchers and students, outreach specialists, and coastal community members in both Tillamook County, OR and Grays Harbor County, WA who are assessing climate change impacts and associated evolving community and ecosystem resilience.

\section{ALTERNATIVE COASTAL FUTURES APPROACH}

Through sustained engagement with coastal stakeholders, we are co-developing an alternative scenario modeling tool (Envision) to explore adaptation strategies for reducing vulnerability to coastal hazards based on a variety of drivers of change. Envision is a spatially explicit multi-agent modeling platform supporting scenario-based planning to examine interactions between the coupled human and natural coastal system (Bolte et al., 2007). Probabilistic simulations of extreme total water levels (Serafin and Ruggiero, 2014), long-term coastal change projections, and storm-induced beach and dune erosion allow us to capture the impacts of SLR, wave climate variability, and the El Niño Southern Oscillation under a range of climate change scenarios through the end of the century. Additionally, we are exploring a range of co-developed alternative futures related to policy decisions and socioeconomic trends using input from stakeholders.

\section{RESULTS}

We are quantifying the impact of both policy scenario narratives and climate change scenarios on a range of stakeholder defined metrics. Co-developed policy scenarios include: 'Status Quo' (a continuation of present day policies), 'Hold the Line' (policies are implemented that involve resisting environmental change in order to preserve existing infrastructure and human activities), 'Re-Align' (policies are implemented that involve changing human activities to suit the changing environment and/or prioritize habitat protection and conservation), and 'Laissez-Faire' (existing policies are relaxed in the model such that existing homes, infrastructure, and new development all trump the protection of coastal resources, public rights, recreational use, beach access, and scenic views). Policies that move people and buildings away from coastal hazards are most successful in protecting property from flooding impacts (Figure 1) whereas policies that permit the construction of engineered backshore protection structures better protect property from erosion impacts. In some scenarios, model results suggest severe reductions in beach accessibility (one metric highly valued by our coastal stakeholders) by the end of century, due to the cumulative placement of riprap backshore protection structures.

\section{DISCUSSION}

In general, model results suggest that human decisions can introduce greater variability to the impacts to the landscape by coastal hazards than climate change uncertainty (Figure 1). By quantifying uncertainty within the Envision framework, this work is helping to determine the relative impact of policy and management decisions on the resilience of Pacific Northwest coastal communities under a range of future climate scenarios. Understanding the impacts of community decisions and climate change will allow for the determination of best practices with respect to adaptation policies.

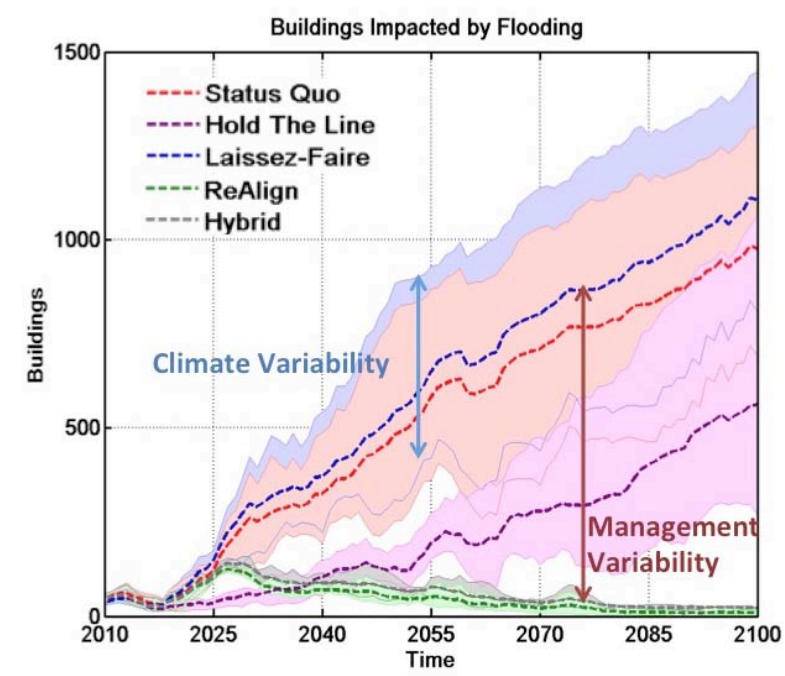

Figure 1 - Number of buildings in Tillamook County, OR expected to be impacted by coastal flooding under a range of policy (line colors) and climate change (width of shaded regions) scenarios.

\section{REFERENCES}

Bolte, Hulse, Gregory and Smith (2007): Modeling biocomplexity -- agents, landscapes and alternative futures. Environmental Modeling and Software 22(5): 570-579.

Serafin and Ruggiero (2014): Simulating extreme total water level events using a time-dependent, extreme value approach, Journal of Geophysical Research - Oceans, 119, 6305-6329, doi: 10.1002/2014JC010093. 